\title{
Modeling and Analysis of Wind Energy Conversion Systems Using Matlab
}

\author{
P.Kumar*, A.Vinoth Kumar \\ Power Systems Division, Assistant Professor DEEE, P.A. College of Engineering and Technology, Pollachi \\ Power Electronics and Drives, Assistant Professor DEEE, P.A. College of Engineering and Technology,
} Pollachi

\begin{abstract}
This paper presents modeling and analysis of Wind Energy Conversion Systems (WECS) using MATLAB version R2009a. This paper gives the modeling of the various components wind turbine, generator, controller system, rectifier-inverter, battery, other load equipments including transformer and grid that together form the Wind Energy Conversion system. A test case for the Wind Energy Conversion System has been formed with the aid of the MATLAB version R2009a and also the suggest the ways of improving the stability of the Wind Energy Conversion System (WECS) on interface with the grid.
\end{abstract}

Keywords: Wind Energy Conversion System (WECS), wind turbine, generator, controller system, rectifierinverter, transformer, grid.

\section{Introduction}

The conventional energy sources such as coal, fossil fuels have greater impact on the environment. Futher with the present day scenario the fossil fuels are getting depleted at a faster rate and the energy reserves may last only for few years. In order to meet the growing energy demand and to protect the environment, the need of the hour is to look in for the renewable energy sources. Wind is one of the promising energy sources that serve to meet the growing energy demand. The growing concern about the emissions from the fossil fuel generation and increased government support has helped flourish wind power installation in India and abroad. Provisions of incentives instituted by the Ministry of New \& Renewable Energy (MNRE) have made the wind electricity competitive in India.The need of energy generation, the potential and the technological capacity were the reasons to foster the emergence of wind energy.

Wind is air in motion and this energy is derived from solar energy. Wind in general is produced by the uneven solar heating of the earth's atmosphere. The kinetic energy of the wind is used to impart rotational motion to the wind turbine. The shaft of the wind turbine is coupled to the shaft of the electric generator. The electric generator can provide power over a region acting as standalone or providing power to the grid.

The Wind Energy Conversion System (WECS) can be used in two ways. The first being isolated standalone system employed to cater the needs of small townships or small scale industries located at far off places. Usually these systems are set up with the objective to avoid transmission costs over long distances. The second being Grid connected system where emphasis is provided on integration of renewable energy systems into the grid, which leads to increased energy efficiency, robustness of the system, voltage support, diversification of energy sources, reduced transmission and distribution losses and reliability of the system.

\section{Variable-Speed And Constant- Speed Wind Turbines}

A major distinction in the wind turbines includes variable and constant speed wind turbines i.e. the rotor is allowed to run at variable speed or constrained to operate at constant speed. The constant speed wind turbines allow the use of simple generators whose speed is fixed by the frequency of the electrical system. Although the power electronics needed for variable speed wind turbines are more expensive, this type of turbines can spend more time operating at maximum aerodynamic efficiency than constant speed turbines. This can be seen clearly if the performance coefficient, $C_{p}$ of a wind turbine is plotted against the tip speed ratio, $\lambda$.

The tip speed ratio, $\lambda$, is defined as the ratio between the speed of the tips of the blades of the wind turbine and the speed of the wind.

$$
\lambda=\frac{v_{\text {tip }}}{v_{\text {wind }}}=\frac{\omega \cdot R}{v}
$$

where $\omega$ is the blades angular velocity $(\mathrm{rad} / \mathrm{s}), R$ the rotor radius $(\mathrm{m})$ and $v$ the wind speed $(\mathrm{m} / \mathrm{s})$. 
The coefficient of performance, $C_{p}$, is defined as the fraction of energy extracted by the wind turbine of the total energy that would have flowed through the area swept by the rotor if the turbine had not been there.

$$
C_{p}=\frac{P_{\text {extracted }}}{P_{\text {wind }}}
$$

The coefficient of performance $C_{p}$ has a theoretical optimum of 0.59 . Only a portion of the power in the wind can be converted to useful energy by wind turbine. The power available for a wind turbine is equal to the change in kinetic energy of the air as it passes through the rotor. This maximum theoretical $C_{p}$ was formulated in 1919 by Betz and applies to all types of wind turbines.

A typical $C_{p}$ vs $\lambda$ characteristics is depicted in the figure.1.The figure.1 represents the characteristics of coefficient of performance, $C_{p}$ versus tip speed ratio, $\lambda$.From figure. 1 we infer that maximum value of $C_{p}$ i.e. 0.5 is achieved for a tip speed ratio of 10 and pitch angle of 0 . For a fixed-speed wind turbine, where $\omega$ is constant, this corresponds to a particular wind speed. For all other wind speeds the efficiency of the turbine is reduced. The aim of variable-speed wind turbines is to always run at optimal efficiency, keeping constant the particular $\lambda$ that corresponds to the maximum $C_{p}$, by adapting the blades velocity to the wind speed changes. Hence, variable speed wind turbines are designed to operate at optimum energy efficiency, regardless of the wind speed.

On the other hand, due to the fixed-speed operation for constant speed turbines, all fluctuations in the wind speed are transmitted as fluctuations in the mechanical torque and then as fluctuations in the electrical power grid. This together with the increased energy capture obtained by using a variable-speed wind turbine provides enough benefit to make the power electronics cost effective .Therefore, the wind industry trend is to design and construct variable-speed wind turbines.

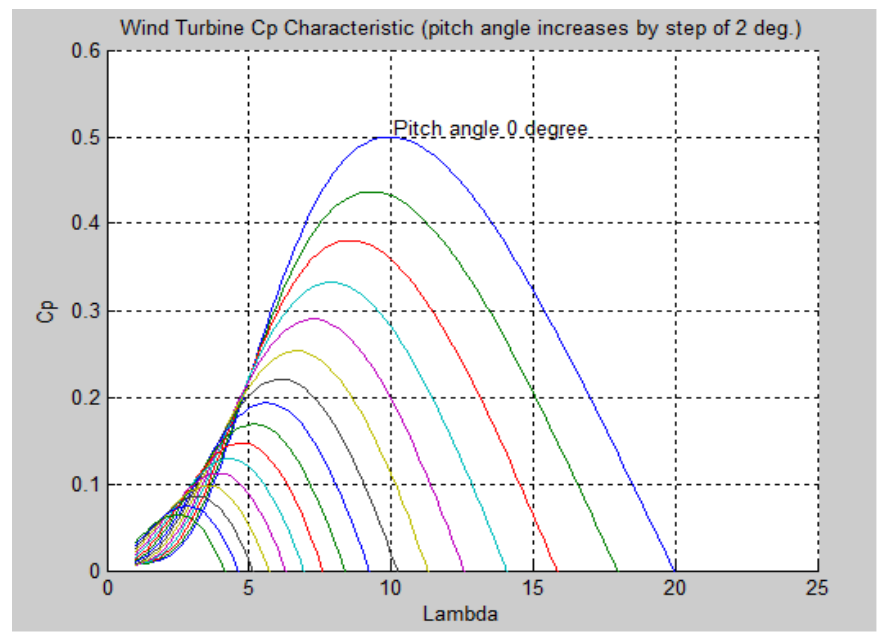

Fig.1 $C_{p}$ vs $\lambda$ characteristics

The figure.2 depicts the characteristics of the $P, \lambda, C_{p}$ versus the wind speed of a typical wind energy conversion system 


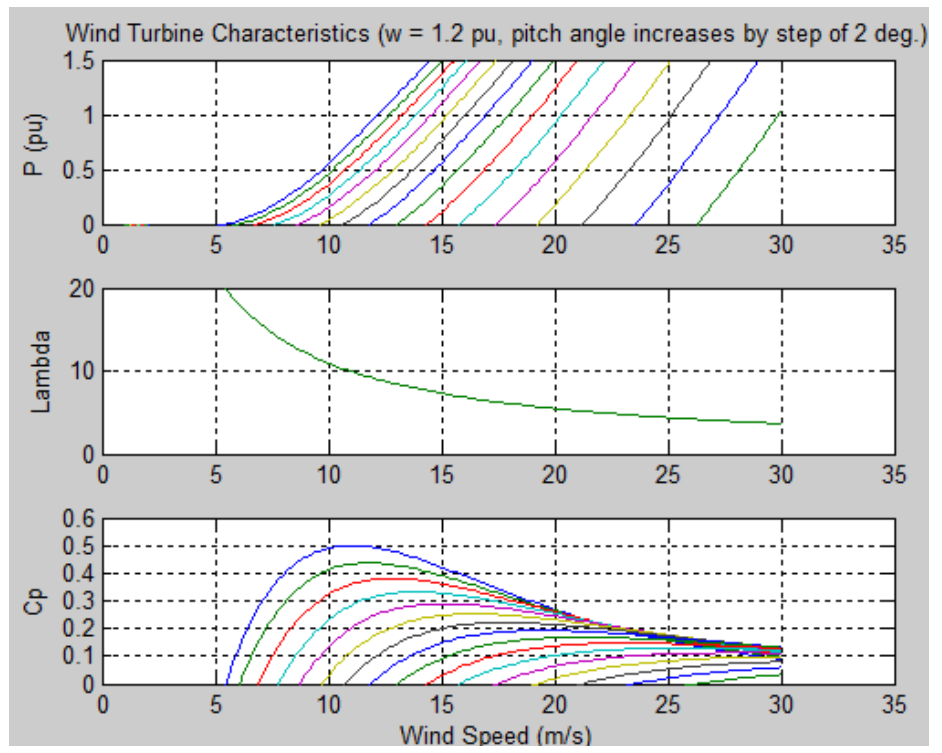

Fig.2 $P, \lambda, C_{p}$ vs wind speed characteristics

\section{Modeling Of Wind Energy Conversion System}

The kinetic energy in a flow of air through a unit area perpendicular to the wind direction is $\frac{1}{2} \cdot v^{2}$ per mass flow rate. For an air stream flowing through an area A the mass flow rate is $\rho . A . v$,therefore the power in the wind is given by,

$$
\begin{aligned}
P & =(\rho \cdot A \cdot v) \cdot \frac{1}{2} \cdot v^{2} \\
& =\frac{1}{2} \cdot \rho \cdot A \cdot v^{3}
\end{aligned}
$$

where,

$\rho$ is the air density $\left(\mathrm{kg} / \mathrm{m}^{3}\right)$

$A$ the area $\left(m^{2}\right)$

$v$ the wind speed $(m / s)$

$P$ the power of the wind (watts or $J / s$ )

A typical wind energy conversion system is represented in the figure.3.

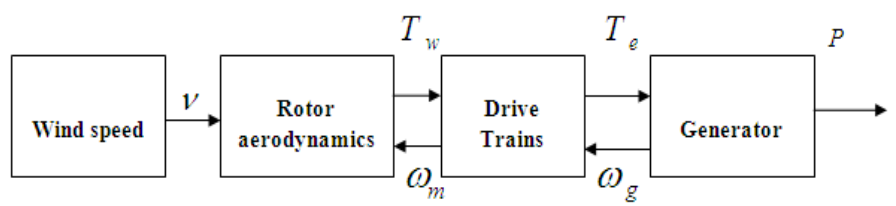

Fig.3 A typical wind energy conversion system

The wind turbine model, consisting of the rotor aerodynamics, drive train and electrical generator model represented in the figure. 3

\subsection{MODELLING OF THE BLADES}

The wind turbine blades extract the kinetic energy in the wind and transform it into mechanical energy. The kinetic energy in air of an object of mass $m$ moving with speed $v$ is given by 


$$
E=\frac{1}{2} \cdot m \cdot v^{2}
$$

The power in the moving air (assuming constant speed velocity) is equal to

$$
P_{w}=\frac{d E}{d t}=\frac{1}{2} \cdot m \cdot v^{2}
$$

where $\boldsymbol{m}$ is the mass flow rate per second. When the air passes across an area A swept by the rotor blades, the power in the air can be computed using (3).

The power extracted from the wind is given by

$$
P_{B L A D E}=C_{p}(\lambda, \beta) \cdot P_{w}=C_{p}(\lambda, \beta) \cdot \frac{1}{2} \cdot \rho \cdot A \cdot v^{3}
$$

The power factor has a maximum theoretical value $C_{p}=0.593$. The rotor power coefficient is usually given as a function of two parameters: the tip-speed ratio $\lambda$ and the blade pitch angle $\beta$ (in degrees).

The blade pitch angle $\beta$ is defined as the angle between the plane of rotation and the blade crosssection chord.

The rotor torque $T_{w}$ can be computed using the expression

$$
T_{w}=\frac{P_{B L A D E}}{\omega_{m}}=\frac{(1 / 2) \cdot C_{p}(\lambda, \beta) \cdot \rho \cdot A \cdot v^{3}}{\omega_{m}}
$$

The area covered by the blades is given by

$$
A=\pi \cdot R^{2}
$$

substituting Eq.(8) in Eq.(7)

$$
T_{w}=\frac{(1 / 2) \cdot \pi \cdot C_{p}(\lambda, \beta) \cdot \rho \cdot R^{2}}{\omega_{m}} \cdot v^{3}
$$

The power coefficient $C_{p}$ can be defined as a function of the tip-speed ratio and the blade pitch angle as follows

$$
C_{p}(\lambda, \beta)=c_{1} \cdot\left(c_{2} \cdot \frac{1}{\gamma}-c_{3} \cdot \beta-c_{4} \cdot \beta^{x}-c_{5}\right) e^{-c_{6} \cdot \frac{1}{\gamma}}
$$

with $\gamma$ defined as

$$
\frac{1}{\gamma}=\frac{1}{\lambda+0.08 \beta}-\frac{0.035}{1+\beta^{3}}
$$

where the constant values $c_{1}-c_{6}$ are given as $c_{1}=0.5, c_{2}=116, c_{3}=0.4, c_{4}=0, c_{5}=5, c_{6}=21$. 


\subsection{MODELLING OF THE DRIVE TRAIN}

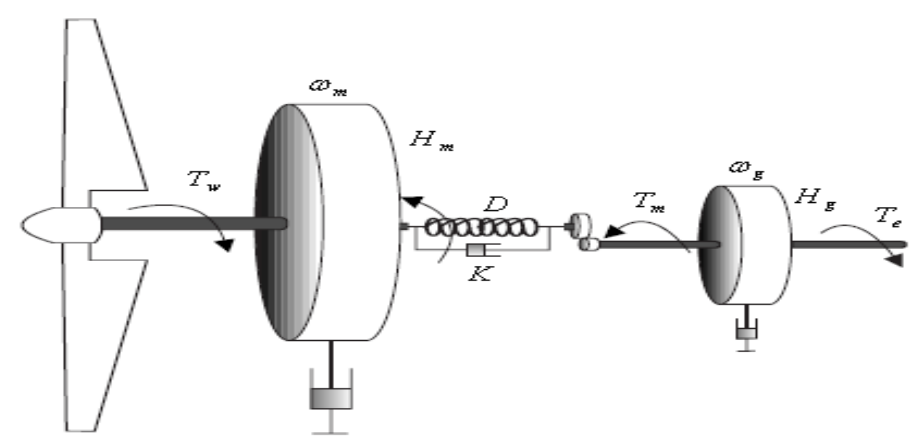

Fig.4 Drive train dynamics

The equation of motion of the induction generator is given by

$$
H_{g} \cdot \frac{d \omega_{g}}{d t}=T_{e}+\frac{T_{m}}{n}
$$

The mechanical torque $T_{m}$ can be modeled with the following equation

$$
\begin{aligned}
& T_{m}=K \cdot \frac{\theta}{n}+D \cdot \frac{\omega_{g}-\omega_{m}}{n} \\
& \frac{d \theta}{d t}=\omega_{g}-\omega_{m}
\end{aligned}
$$

where

$n$ is the gear ratio

$\theta$ is the angle between the turbine rotor and

the generator rotor

$\omega_{m}$ is the turbine speed

$\omega_{g}$ is the generator rotor speed

$H_{m}, H_{g}$ are the inertia constants of turbine and generator respectively

$K$ is the drive train stiffness

$D$ is the damping constant

$T_{w}$ is the torque provided by wind

$T_{e}$ is the electromagnetic torque.

\subsection{MODELLING OF THE ASYNCHRONOUS GENERATOR}

The modelling of the asynchronous generator plays an important role in the design of the wind energy conversion system. The asynchronous generator has three phase stator armature winding $\left(A_{s}, B_{s}, C_{s}\right)$ and a three phase rotor winding $\left(A_{R}, B_{R}, C_{R}\right)$ as shown in the figure below.

The mathematical model of an asynchronous generator for power system analysis is usually based on the following assumptions

1. The stator currents are positive when flowing towards the network

2. The real and reactive power are positive when fed into grid. 


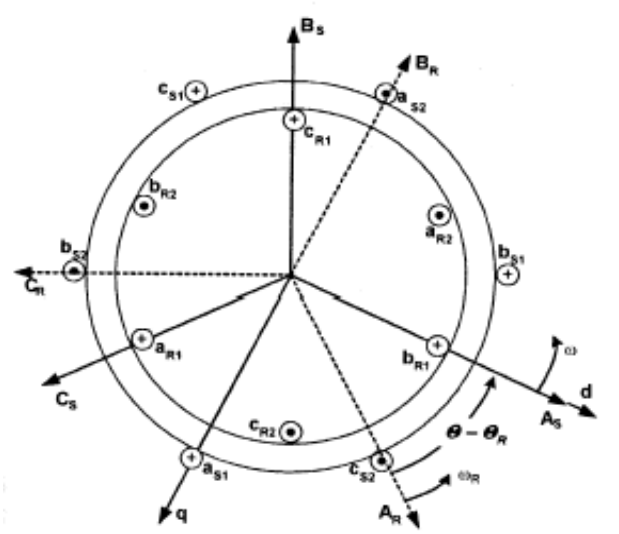

Fig.5 windings in the asynchronous generator

3. The stator and rotor windings are placed sinusoidally along the air-gap as far as the mutual effect with the rotor is concerned.

4. The stator slots cause no appreciable variations of the stator inductances with rotor position.

5. The rotor slots cause no appreciable variations of the stator inductances with rotor position.

6. Magnetic hysteresis and saturation effects are negligible.

7. The stator and rotor windings are symmetrical.

8. The capacitance of all the windings are neglected.

The set of equations of the asynchronous generator model is usually converted into a model related to an arbitrarily set reference frame called $o d q$ reference frame model. The $d q$ axis representation of induction generator is used for simulation, taking flux linkage as basic variable. It is based on fifth-order two axis representations. Mathematical transformations are used in the analysis and simulation of three-phase systems, mostly to decouple variables, to facilitate the solution of difficult equations with time-varying coefficients. Park's transformation decouples and rotates the stator variables into a $d q$ reference frame. The positive d-axis of the $d q$ frame is aligned with the magnetic axis of the field winding, that of the positive q-axis is ahead in the direction of rotation or lead the positive d-axis by $\frac{\pi}{2}$. ds and qs correspond to stator direct and quadrature axes.dr and qr correspond to rotor direct and quadrature axes.

For power system transient studies, the inclusion of the network transients and generator stator transients increases the overall system model, thus limiting the size of the system that can be simulated. Furthermore, a small time step is required for numerical integration resulting in an increased computational time. For these reasons, it has become conventional to reduce the order of the generator and neglect the network transients for stability analysis. A standard method of reducing the order of the induction generator model was considered where the rate of change of stator flux linkage is neglected.

To be able to simulate the induction generator and wind generation system, an equation relating $V_{d s}, V_{q s}$, the stator direct and quadrature axis voltages and $I_{d s}, I_{q s}$, the stator direct and quadrature axis currents is required. The complete model of an asynchronous generator, expressed in a $o d q$ reference frame rotating at synchronous speed and taking positive currents going out from the machine consists of the following equations.

$$
\begin{aligned}
& \varphi_{d s}=X_{s} \cdot I_{d s}+X_{m} \cdot I_{d r} \\
& \phi_{q s}=X_{s} \cdot I_{q s}+X_{m} \cdot I_{q r} \\
& \phi_{d r}=X_{r} \cdot I_{d r}+X_{m} \cdot I_{d s} \\
& \phi_{q r}=X_{r} \cdot I_{q r}+X_{m} \cdot I_{q s}
\end{aligned}
$$

Equations (15),(16),(17),(18) represent the flux linkage equations on direct axis and quadrature axis respectively. 


$$
\begin{aligned}
& V_{d s}=-R_{s} \cdot I_{d s}+\omega_{s} \cdot \phi_{q s} \\
& V_{q s}=-R_{s} \cdot I_{q s}-\omega_{s} \cdot \phi_{d s} \\
& 0=-R_{r} \cdot I_{d r}+s \cdot \omega_{s} \cdot \phi_{q r}-\frac{d \phi_{d r}}{d t} \\
& 0=-R_{r} \cdot I_{q r}-s \cdot \omega_{s} \cdot \phi_{d r}-\frac{d \phi_{q r}}{d t}
\end{aligned}
$$

Equations (19),(20),(21),(22) represent the voltage equations on direct axis and quadrature axis respectively.

The electrical parameters of the machine $R_{s}, X_{s}, X_{m}, R_{r}, X_{r}$ stand for the stator resistance and reactance, mutual reactance and rotor resistance and reactance respectively.

The slip of the rotor is defined as follows,

$$
s=\frac{\omega_{s}-\omega_{g}}{\omega_{s}}
$$

The electrical torque is given by

$$
T_{e}=\phi_{q r} \cdot I_{d r}-\phi_{d r} \cdot I_{q r}
$$

The developed torque is positive for motoring operation and negative for generation operation.

The wind turbine active, reactive and apparent power output are given by the following equations

$$
\begin{gathered}
P_{\text {active }}=V_{d s} \cdot I_{d s}+V_{q s} \cdot I_{q s} \\
Q_{\text {reactive }}=V_{q s} \cdot I_{d s}-V_{d s} \cdot I_{q s} \\
S=P_{\text {active }}+Q_{\text {reactive }} \\
S=V_{d s} \cdot I_{d s}+V_{q s} \cdot I_{q s}+V_{q s} \cdot I_{d s}-V_{d s} \cdot I_{q s}
\end{gathered}
$$

In order to reduce the overall system model and to reduce the computational time involved, the system is modelled with the order of the generator is reduced and the network transients are neglected for stability studies.

IV. Simulation And Results

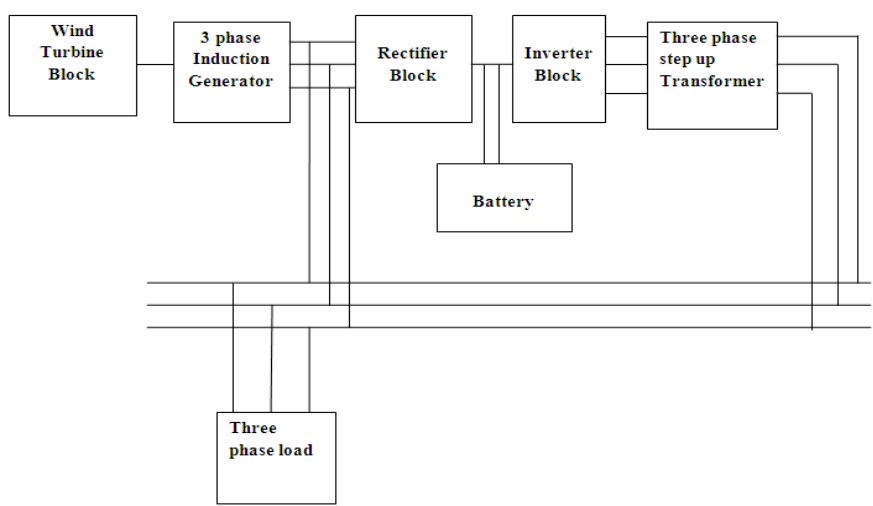

Fig.6 Wind Energy Conversion System Model 
The figure 6 gives the complete model of the wind energy conversion system model formulated in MATLAB version R2009a.The simulation of the wind energy conversion system before and after interfacing with the utility grid is represented in the figures 7 and 8 respectively.

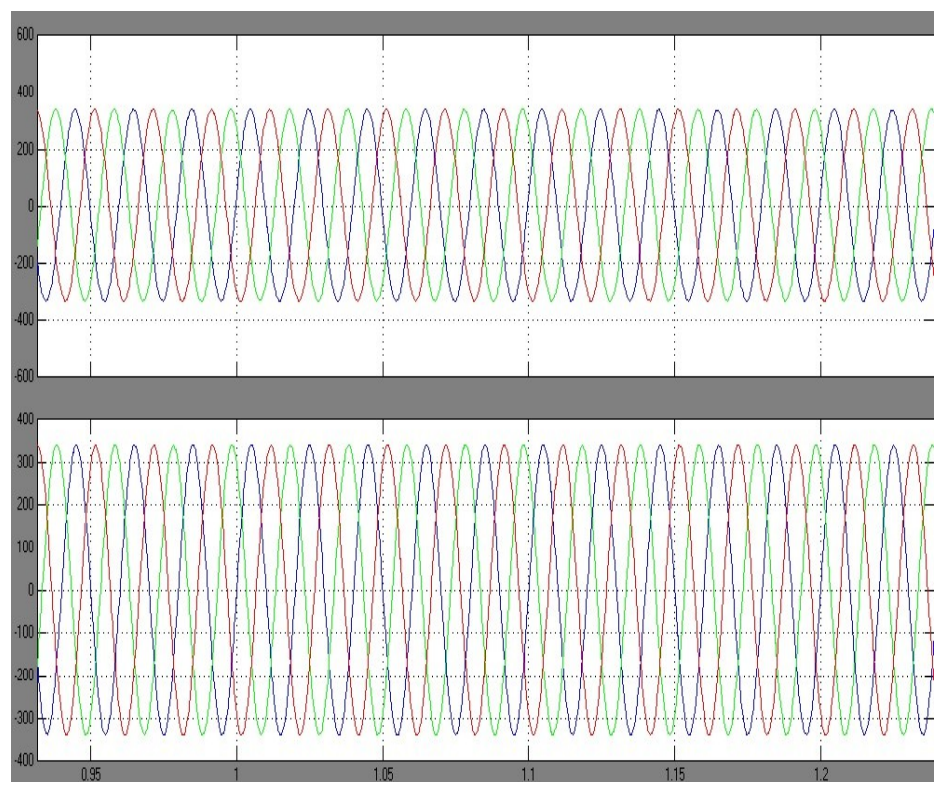

Fig.7 WECS simulation before grid interfacing

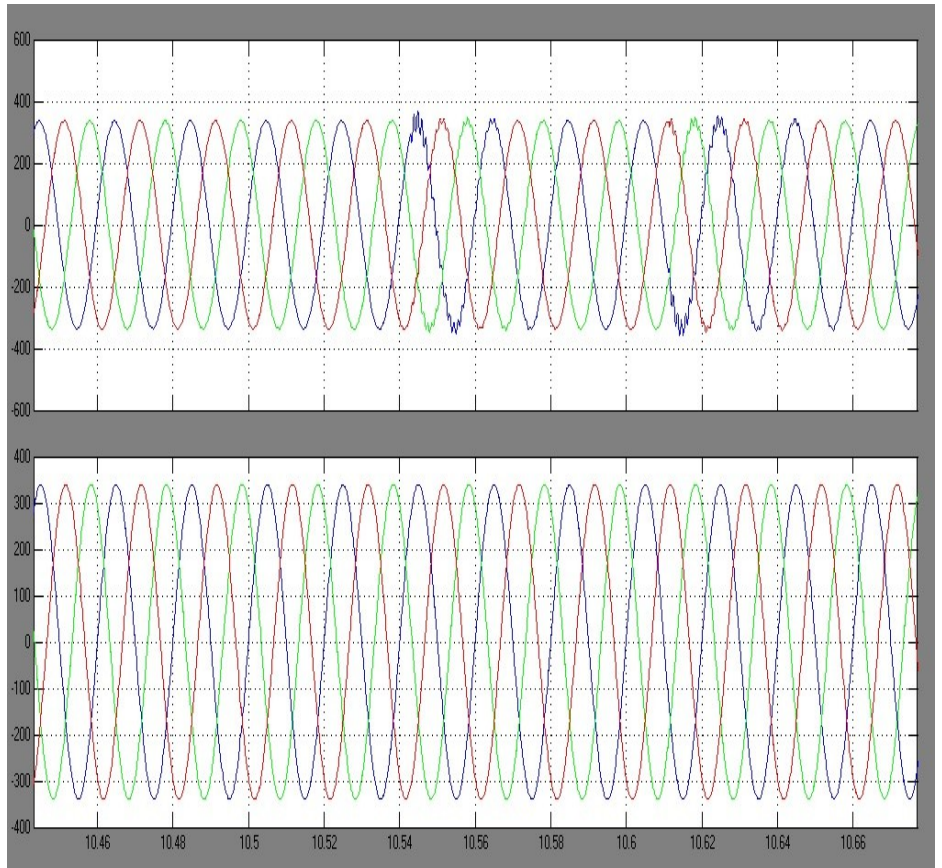

Fig.8 WECS simulation after grid interfacing

From figure 7 we observe before the interface of the wind energy conversion system with grid, the utility grid voltage $V_{a b c}$ and current $I_{a b c}$ remains sinusoidal without any disturbances in $V_{a b c}$ and $I_{a b c}$ respectively.

From figure 8 we observe after the interface of wind energy conversion system with the grid, the utility grid voltage $V_{a b c}$ remains unaffected but considerable disturbances are observed in the grid current $I_{a b c}$. These disturbances generally arises due to variable nature of the wind.Inorder to improve the stability of 
wind energy conversion system on interface with the grid the stability of the wind energy conversion system has to be improved.

For the analysis of the stability and the dynamic performance of the wind energy conversion system a detailed model of the wind energy conversion system has been formed in MATLAB R2009a. The model is depicted in the figure 9

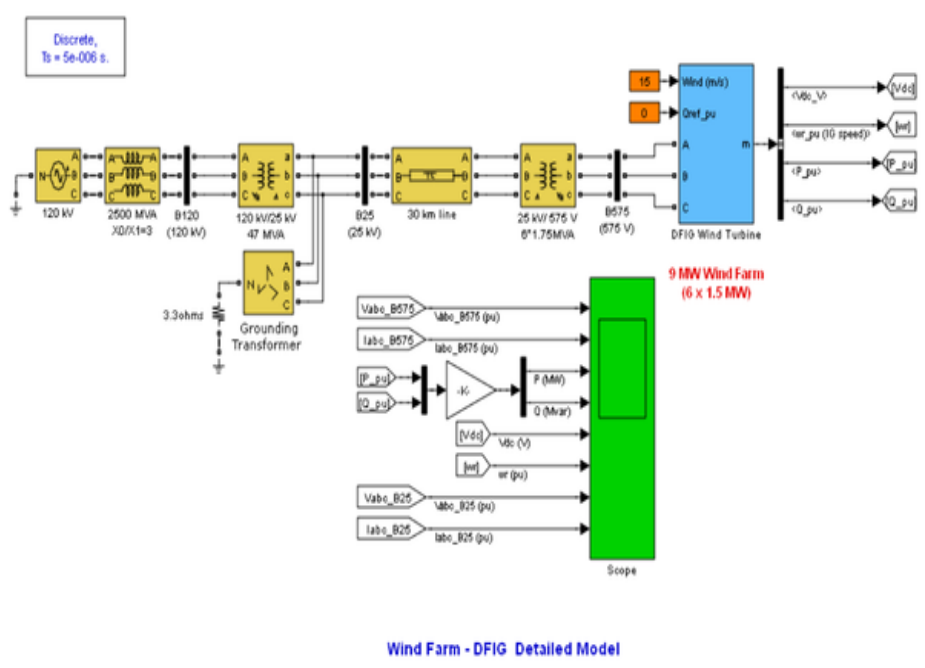

Fig.9 Detailed model of Wind Energy Conversion System

The detailed model includes the detailed representation of power electronic IGBT converters.Inorder to achieve an acceptable accuracy with $1620 \mathrm{~Hz}$ and $2700 \mathrm{~Hz}$ switching frequencies the model must be discretized at a relatively small time step( 5 micro seconds).This model is well suited for observing harmonics and control system dynamic performance over relatively short periods of time.

A $9 \mathrm{MW}$ wind farm consisting of six $1.5 \mathrm{MW}$ wind turbines connected to a $25 \mathrm{kV}$ distribution system exports power to a $120 \mathrm{kV}$ grid through a $30 \mathrm{~km}, 25 \mathrm{kV}$ feeder. Wind turbines using a doubly-fed induction generator (DFIG) consist of a wound rotor induction generator and an AC/DC/AC IGBT-based PWM converter. The stator winding is connected directly to the $60 \mathrm{~Hz}$ grid while the rotor is fed at variable frequency through the AC/DC/AC converter. The DFIG technology allows extracting maximum energy from the wind for low wind speeds by optimizing the turbine speed, while minimizing mechanical stresses on the turbine during gusts of wind.

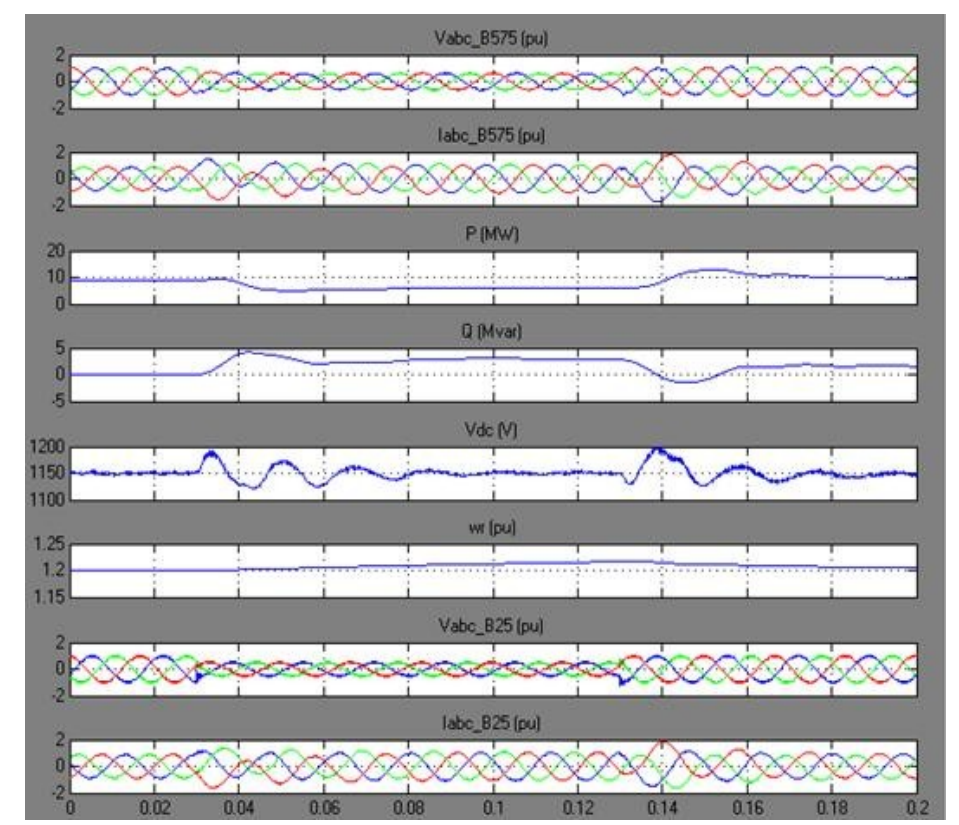

Fig.10 Simulation results of detailed model of Wind Energy Conversion System 
In this model the wind speed is maintained constant at $15 \mathrm{~m} / \mathrm{s}$. The control system uses a torque controller in order to maintain the speed at $1.2 \mathrm{pu}$. The reactive power produced by the wind turbine is regulated at 0 Mvar.This model is used to analyse the steady-state operation of the DFIG and its dynamic response to voltage sag resulting from a remote fault on the $120-\mathrm{kV}$ system.

The simulation results are provided in figure 10.From the simulation results we observe the DFIG wind farm produces $9 \mathrm{MW}$.The corresponding turbine speed is $1.2 \mathrm{p}$.u. of generator synchronous speed .The DC voltage is regulated at $1150 \mathrm{~V}$ and the reactive power is kept at 0 Mvar.At $\mathrm{t}=0.03 \mathrm{~s}$ the positive-sequence voltage suddenly drops to 0.5 p.u. causing an oscillation on the DC bus voltage and on the DFIG output power. During the voltage sag the control system tries to regulate DC voltage and reactive power at their set points $(1150 \mathrm{~V}, 0$ Mvar).The system recovers in approximately 4 cycles.

\section{Conclusion}

This paper gives a detailed modelling of the wind energy conversion systems and the impacts of interfacing the wind energy conversion system with the grid. From the simulation results we infer that considerable harmonics in the current are observed on interface of the wind energy conversion system with the grid. However these harmonics can be reduced by employing control system with torque controller for speed regulation and voltage regulator for voltage regulation. A MATLAB version R2009a demo model is taken for analysis of wind energy conversion system. The test results from analysis of wind energy conversion system indicates that design of control system with suitable torque controller and voltage regulator can improve the performance of wind energy conversion systems under the fault conditions.

\section{Scope Of Future Work}

This work could be extended for future research by the design of control system with different controllers and by making analysis of its performance under various fault conditions.

\section{References}

[1] UCTE, Union for coordination of transmission of electricity, Wind Power in the UCTE interconnected System, November 2004

[2] E. Spooner and A.C. Williamson, Direct coupled permanent magnet generators for wind turbine applications, IEE Proceeding, Electric Power Applications. Vol. 143, Nº1, pp.1-8, January, 1996.

[3] M.R.Dubois, H.Polinder and J.A. Ferreira, Comparison of generators topologies for direct -drive wind turbines, ECM 92, Manchester UK, pp. 761-765, 1992.

[4] Thomas Ackerman, Wind Power in Power Systems, Royal Institute of Technology Stockholm, Sweden, Edition: John Wiley and sons, Ltd, 2005.

[5] M.G.Gracia_, M. P. Comech, J.Salla and A. Llombart, Modelling wind farms for grid disturbance studies, Renewable Energy 33 (2008)2109-2121.

[6] T.Petru and T.Thirnger, Modelling of wind turbines for power system studies, IEEE Trans. Energy Convers. Vol. 17, N4, pp. 1132-1139, Nov. 2002.

[7] E.S.Abdin and W.Xu, Control design and dynamic performance analysis of a wind turbine-induction generator unit, IEEE Trans. Energy Convers. Vol. 15, N¹, pp. 91-96, March. 2000.

[8] G.Saccomando, J. Svensson and A.Sannino, Improving voltage disturbance rejection for variable-wind speed wind turbine, IEEE Trans, Energy Convers, Vol. 17, N³, pp. 422-428, June 2002.

[9] http://www.creswindfarm.gr/site1/Articles/ V47 US.pdf

[10] C.M. Ong, Dynamic Simulation of Electric Machinery using Matlab/Simulink, Prentice-Hall PTR, Upper Saddle River, New Jersey,

1998 .

[11] Z.Miao and L.Fan. The art of modeling and simulation of induction generator in wind generation applications using high-order model, Simulation Modelling Practice and Theory Vol. 16, pp. 1239-1253, 2008

[12] I.Zubia, X. Ostolaza, A.Susperregui and G.Tapia, Complete wind farm electromangetic transient modelling for grid integration studies, Energy Conversion and Management, Vol. 50(3), March 2009, pp. 600-610.

[13] M.Martins, A.Perdana, P.Ledesma, E.Agneholm and O.Carlson, Validation of fixed speed wind turbine dynamics models with measured data, Renewable Energy, Vol.38(8), July 2007,pp.1301-1316.

[14] M.L.Doumbia and A.Traoré, Modélisation et simulation d'une machine asynchrone à cage à l'aide du logiciel Matlab/simulink, MSAS, Bamako, July 8-12, 2002;

[15] S.Derriche, H. Djebrani and DJ.Djemai, modélisation et simulation d'un générateur éolien connecté au réseau à l'aide du logiciel MATLAB/SIMULINK,Mémoired'ingénieur d'état de l'Université Mouloud Mammeri de Tizi-Ouzou, Algérie, Septembre 2008.

[16] L.Leclercq, Apport du stockage inertiel associés à des éoliennes dans un réseau électrique en vue d'assurer des services systèmes.Thèse de Doctorat, Laboratoire d'Electrotechnique et d'Electronique de Puissance de Lille, Le 14 décembre 2004.

[17] P.M. Anderson, and Anjan Bose, Stability simulation of wind turbine systems, IEEE

Transactions on Power Apparatus and Systems, Vol. 102, No. 12, pp.3791-3795, December 1983.

[18 ] N. Laverdure, S. Bacha, D. Roye, B. Raison, and F. Dumas, Elements of modeling of wind power systems with energy management: two structures in comparison, IEEE 28th Annual Conference of the Industrial Electronics Society , Vol. 2, pp.1083-1088, November 2002.

[19] L.Krichen, B.Francois and A.Ouali, A fuzzy logic supervisor for active and reactive power control of fixed speed wind energy conversion system, Electric Power System Research, Vol. 78, pp. 418-424, 2008.

[20] F.poitiers, Etude et commande de génératrice asynchrone pour l'utilisation de l'énergie éolienne, Thèse de doctorat .Univ ersité de Nantes, France, 19 Décembre 2003. 